\title{
Sugar-Sweetened Beverage Consumption Among a Subset of Canadian Youth
}

\author{
Lana Vanderlee, BSc ${ }^{a}$ Steve Manske, EdD ${ }^{\mathrm{b}}$ Donna Murnaghan, RN, PhDc Rhona Hanning, PhD, RD, FDC d David Hammond, PhD
}

\section{ABSTRACT}

BACKGROUND: Sugar-sweetened beverages (SSBs) may play a role in increased rates of obesity. This study examined patterns and frequencies of beverage consumption among youth in 3 distinct regions in Canada, and examined associations between beverage consumption and age, sex, body mass index (BMI), physical activity and dieting behavior, as well as beverage displacement.

METHODS: The study included data from 10,188 youth (ages 13-18) from Hamilton and Thunder Bay, Ontario, and Prince Edward Island (PEI) in 2009 to 2010 . The study used in-school self-reported surveys with 12 questions regarding beverage consumption during the previous day, along with self-reported height, weight, physical activity levels, and demographic information. Logistic regression analyses were conducted to examine variables associated with SSB intake.

RESULTS: Overall, $80 \%$ of youth consumed at least 1 SSB in the previous day, with $44 \%$ consuming 3 or more SSBs. Youth in Thunder Bay consumed significantly more SSBs than Hamilton and PEI, and youth in Hamilton consumed more SSBs than PEI. Boys consumed significantly more SSBs than girls. Older and more physically active youth consumed significantly fewer SSBs. No significant association between BMI and SSB consumption was observed in any model. A modest positive correlation was identified between SSB consumption and milk $(r=.06, p<.001)$ and 100\% fruit juice $(r=.10, p<.001)$.

CONCLUSIONS: A large proportion of youth consumed SSBs, many at high levels. Research evaluating SSB policy and interventions should be considered a priority.

Keywords: sugar-sweetened beverages; food habits; youth or adolescents; beverage consumption.

Citation: Vanderlee L, Manske S, Murnaghan D, Hanning R, Hammond D. Sugar-sweetened beverage consumption among a subset of Canadian youth. J Sch Health. 2014; 84: 168-176.

Received on January 6, 2012

Accepted on January 19, 2013

$\mathrm{O}$ besity is a global public health issue of increasing importance. Globally, 1.4 billion people are overweight, and of these, over 500 million people are obese. ${ }^{l}$ Canada is among the countries that have seen a large increase in obese and overweight individuals: obesity rates nearly doubled from 1981 to $2008 .^{2}$ Current estimates indicate that nearly one fourth of Canadian adults are obese and 37\% are overweight based on body mass index (BMI), whereas $17 \%$ of Canadian children aged 2 to 17 are overweight and $9 \%$ are obese. ${ }^{3}$

Excess weight is associated with a range of health problems during childhood, including increased prevalence of cardiovascular, endocrine, gastroenterological, and pulmonary issues, as well as psychosocial problems. ${ }^{4}$ Patterns of overweight and obesity in childhood and adolescence are strongly associated with overweight and obesity in adulthood. ${ }^{5}$ In adulthood, excess body weight increases the risk of a range of chronic diseases, including cardiovascular disease and osteoarthritis, type 2 diabetes, and certain types of cancers. ${ }^{6}$ As a result, reducing childhood obesity in Canada has been identified as a national priority. ${ }^{7}$

Increased consumption of sugar-sweetened beverages (SSBs) has been identified as 1 potential cause for the increase in obesity. Sugar-sweetened beverages can be defined as "soda sweetened with sugar, corn syrup, or other caloric sweeteners and other carbonated and un-carbonated drinks, such as sports and energy drinks," and are of particular concern because of their high caloric content with little to no nutritional value. . $^{2,8}$

Consumption rates for SSBs and beverage-related caloric intake have risen in recent decades. Data

aPhD Student, (lana.vanderlee@uwaterloo.ca), University of Waterloo School of Public Health and Health Systems, 200 University Ave. W, Waterloo, ON N2L 3G1, Canada. bSenior Scientist, Research Associate Professor, (manske@uwaterloo.ca), University of Waterloo Faculty of Applied Health Sciences, Propel Centre for Population Health Impact, 200 University Ave. W, Waterloo, ON N2L 3G1, Canada.

‘Acting Dean and Associate Professor, (dmurnaghan@upei.ca), University of Prince Edward Island School of Nursing, Comprehensive School Health Research Group, 550 University Ave., Charlottetown, PEI C1A 4P3, Canada. 
from 2 nationally representative 24-hour recall surveys conducted in the United States found that between 1994 and 2004, daily caloric intake from SSBs increased by $20 \mathrm{kcal}$ per capita. ${ }^{9}$ Nondiet "regular" soft drinks are the largest contributor of added sweeteners to the American diet, contributing approximately one third of added sweeteners. ${ }^{10}$ Research suggests that Canadian and American children have a similar proportion of energy intake from beverages and total beverage intakes. ${ }^{11} \mathrm{~A}$ recent national survey of 4- to 18-year-old Canadians indicates that beverages comprise approximately $20 \%$ of total calories consumed by children. ${ }^{12}$ Canada has seen an increase of $37 \mathrm{kcal}$ in available energy from soft drinks per day per capita between 1976 and 2007. ${ }^{13}$

Sugar-sweetened beverage consumption has risen concurrently with obesity rates in Canada and internationally, and has been linked to high blood pressure, type 2 diabetes, and metabolic syndrome. ${ }^{14-16}$ Consumption of SSBs may promote weight gain in several ways, including a direct increase in caloric consumption, appetite stimulation or decreased levels of satiation, adverse metabolic effects, and replacement of milk and other beneficial nutrients in the diet. ${ }^{17,18}$ Still, the role of SSBs in the current obesity epidemic is often debated.

Results from systematic reviews and meta-analyses on SSB consumption including cross-sectional, longitudinal, and experimental (randomized-control trial) study designs generally support associations between soft drink consumption, overall energy intake, and body weight. ${ }^{19-21}$ However, 1 meta-analysis employing unique methodological analyses found no significant association between SSB consumption and body weight gain. ${ }^{22}$ This meta-analysis has been criticized for underestimating the effect of beverages on body weight. ${ }^{23}$

Presently, there are conflicting Canadian data on consumption of SSBs and body mass among children and youth. One longitudinal study conducted with "healthy" boys and girls found no significant relationship between sugary drink intake and development of fat mass. ${ }^{24}$ A nationally representative Canadian cross-sectional survey also found that adolescents had no greater odds of obesity with higher levels of soft drink consumption. ${ }^{25}$ In contrast, a longitudinal study of Canadian preschool-aged children found that consumption of SSBs between meals more than doubled the odds of being overweight. ${ }^{26}$ A cross-sectional study in Canadian adolescents also demonstrated significantly higher consumption of SSBs in obese participants compared to nonobese participants and higher consumption of SSBs in males; however, this study used a small sample size with limited generalizability to the larger population. ${ }^{27}$

Recent attention has also focused on the association between consumption of SSBs and of other nutrient-rich beverages, such as milk and 100\% fruit juice. From 1977 to 2001, energy intake from milk in American children 2 to 18 years of age declined by $38 \% .^{28}$ Similar trend data are unavailable for Canadian children. Canadian research suggests that water, milk, and fruit juice account for approximately $60 \%$ of the beverages consumed by youth aged 14 to 18 , with SSBs making up the majority of the difference. $^{12}$ A recent cluster analysis of beverage consumption patterns among Canadian children found that the cluster that consumed the most soft drinks had the lowest calcium consumption. ${ }^{11}$ Currently, more than one third of the Canadian children do not consume enough milk products to meet Canada's Food Guide recommendations. ${ }^{12}$ Overall, displacement of beverages of higher nutritional value with beverages of lower nutritional value has yet to be established.

There is a need for further evidence to examine the SSB trends among youth in Canada. The primary objective of this paper is to characterize beverage consumption patterns among youth in 3 distinct regions in Canada: Thunder Bay and Hamilton, Ontario, and the province of Prince Edward Island (PEI), using a large, school-based sample of students' grades 7 to 12 . A secondary objective of this article is to examine the association between individual factors such as age, sex, BMI, physical activity, and dieting behavior with SSB consumption among this sample. Finally, the study purposes to assess the consumption of milk and $100 \%$ fruit juice in relation to consumption of SSBs, to examine beverage displacement.

\footnotetext{
dAssociate Professor, (rhanning@uwaterloo.ca), Propel Centre for Population Health Impact, University of Waterloo School of Public Health and Health Systems, 200 University Ave. W, Waterloo, ON N2L 3G1, Canada.

eAssociate Professor, (dhammond@uwaterloo.ca), University of Waterloo School of Public Health and Health Systems, Propel Centre for Population Health Impact, 200 University Ave. W, Waterloo, ON N2L 3G1, Canada.

Address correspondence to: David Hammond, Associate Professor, (dhammond@uwaterloo.ca), University of Waterloo School of Public Health and Health Systems, Propel Centre for Population Health Impact, 200 University Ave. W, Waterloo, ON N2L 3G1, Canada.

Funding to collect SHAPES youth data in Hamilton came from the Hamilton Public Health Services, in Thunder Bay from Thunder Bay District Health Unit, and in PEl from the Department of Education and Early Childhood Development. This research was supported by a grant from Canadian Cancer Society Research Institute, as well as Vanier Canada Graduate Scholarship (Vanderlee), CIHR Master's Award (Vanderlee), the Heart and Stroke Foundation of Canada and the CIHR/Training Grant in Population Intervention for Chronic Disease Prevention: A Pan-Canadian Program (Grant No.: 53893) (Vanderlee), Ontario Graduate Scholarships (Vanderlee), the Propel Centre for Population Health Impact, a Canadian Institutes for Health Research New Investigator Award (Hammond), and a Canadian Cancer Society Research Institute Junior Investigator Research Award (Hammond).
} 


\section{METHODS}

\section{Procedure and Participants}

This study is a secondary analysis of cross-sectional data, collected as part of the School Health Action, Planning and Evaluation Surveys (SHAPES). Using a machine-readable questionnaire, SHAPES is a tool that can collect data from grade 5 to 12 students, with modules that assess tobacco use, physical activity, healthy eating, and mental fitness or a combination of the aforementioned topics (http://www. shapes.uwaterloo.ca/).

The data used in this study were collected in 3 regions of Canada: (1) Thunder Bay, Ontario, (2) Hamilton, Ontario, and (3) the province of PEI. Thunder Bay (population 121,986) is located in northern Ontario; Hamilton (population 662,401) is located in southwestern Ontario, separated by more than $1000 \mathrm{~km}$; PEI (population 135,294) is located on the eastern coast of the country. Although all 3 regions have a similar age profile, Thunder Bay has a greater aboriginal population $(7 \%$ as compared to $1 \%$ in Hamilton and PEI), Hamilton has a greater visible minority population $(10 \%$ as compared to $2 \%$ in Thunder Bay and $1 \%$ in PEI), and PEI has a lower average income $(\$ 34,125$ per annum, compared to $\$ 44,331$ in Thunder Bay and $\$ 47,173$ in Hamilton). ${ }^{29}$

Data for the Thunder Bay and Hamilton samples were collected in October/November 2009 and January/February 2010, respectively. Data from PEI were collected January to May 2009 as part of the SHAPES-PEI study, in collaboration with the Youth Smoking Survey.

Students were recruited from middle and secondary schools. Students were recruited from grades 7 to 12 in PEI, and from grades 9 to 12 in Thunder Bay and Hamilton. Individuals under the age of 13 or in less than grade $7(\mathrm{~N}=1887)$ were excluded from the analysis to ensure a similar age range across regions. All surveys used in-class self-administered questionnaires. In PEI, 46 of 69 schools in the province completed the survey, and all schools were eligible to participate. The response rate in PEI was $77.3 \%$ (proportion that completed among potentially eligible students). In Hamilton and Thunder Bay, a convenience sample was selected to participate at the discretion of the local health units. In Hamilton, 10 schools were approached and 8 participated. In Thunder Bay all 9 schools that were approached participated. Response rates for Hamilton and Thunder Bay were not available. All classes in each of the schools took part in the survey, and all consenting students were eligible to participate. Schools in Hamilton and Thunder Bay required active information with passive consent, and PEI schools required active consent for grades 7 to 8 and active information with passive consent for grades 9 to 12 .

\section{Instruments}

Demographics. Demographic variables included age (in years) and sex. Self-reported height (in $\mathrm{cm}$ or inches) and weight (in pounds or $\mathrm{kg}$ ) were collected to calculate BMI. ${ }^{30}$ Body mass index scores were compared to the 2000 Centers for Disease Control and Prevention (CDC) growth charts for age to calculate individual BMI-for-age z-scores. ${ }^{31}$ Body mass index was analyzed as categorical variables, using 4 BMI-for-age weight status categories: underweight $(\mathrm{z}$-score $<5$ th percentile for age); healthy weight (5-85th percentile for age); at risk for overweight (85-95th percentile for age); or overweight (>95th percentile for age). ${ }^{31}$

Beverages. Questions about the frequency of beverage consumption on the previous day were drawn from the Healthy Eating Module of the SHAPES program. Concurrent validation of the module versus Webbased 24-hour diet recall for the same period in 387 students age 10 to 13 yielded significant correlations for all milks, 100\% fruit juice, fruit flavored drinks, and regular pop with intra-class correlation coefficients of 0.26 to 0.62 showing moderate agreement. ${ }^{32}$ Hence, the questionnaire had adequate validity for population level surveillance and for those beverage categories consumed most frequently. Beverage questions stated: "Yesterday, from the time you woke up until the time you went to bed, how many servings of the following did you drink?" followed by 12 categories of beverages. Beverage categories and examples are provided in Table 1. Responses for the PEI survey included $0,1,2,3,4-5$, and 6 or more servings. Hamilton and Thunder Bay survey responses were 0 , $1,2,3,4,5$, and 6 or more servings. Responses were categorized into $0,1,2,3$, and 4 or more servings to standardize across surveys. Beverage measures were used to provide approximations of beverage serving consumption, and do not translate directly into energy intake. A summary variable was created using the sum of beverage servings across the 7 sweetened beverage categories (fruit-flavored drinks, regular soda or soft drinks, sports drinks, high-energy drinks, hot chocolate, cappuccino or frappuccino, slurpees, and shakes) to examine total SSB consumption. This variable was scored for each serving of any of the 7 categories of SSBs, with serving size examples described in Table 1. Dieting behavior was assessed by asking: "Are you currently eating less than usual to lose weight (yes/no)," and was only asked in the PEI survey.

Physical activity. Physical activity measures were assessed using 2 questions regarding moderate and hard physical activities: "HARD physical activities are jogging, team sports, fast dancing, jump-rope, and any other physical activities that increase your heart rate and make you breathe hard and sweat. Mark how many minutes of HARD physical activity you did on each of the last 7 days. This includes physical activity during physical education class, lunch, recess, after 
Table 1. Beverage Categories

\begin{tabular}{|c|c|}
\hline Category & Description \\
\hline \multirow{2}{*}{$\begin{array}{l}\text { White or chocolate milk or soy beverage } \\
100 \% \text { fruit juice or vegetable juice }\end{array}$} & One cup or small carton of milk \\
\hline & $\begin{array}{l}\text { One cup or drinking box-size } \\
\text { serving of } 100 \% \text { orange, apple, or } \\
\text { tomato juice }\end{array}$ \\
\hline Fruit-flavored drinks & $\begin{array}{l}\text { One cup or drinking box-size } \\
\text { serving of Kool-aid }{ }^{\circledR}, \text { Sunny } D{ }^{\circledR}, \\
\text { or lemonade }\end{array}$ \\
\hline \multirow{2}{*}{$\begin{array}{l}\text { Regular (nondiet) pop or soft drinks } \\
\text { Sports drinks }\end{array}$} & One cup or can of pop \\
\hline & $\begin{array}{l}\text { One cup or a small bottle of } \\
\text { Gatorade }{ }^{\circledR}\end{array}$ \\
\hline High-energy drinks & One cup or can of Red Bull॥ \\
\hline $\begin{array}{l}\text { Hot chocolate, cappuccino, or } \\
\text { frappuccino }\end{array}$ & One mug of hot chocolate \\
\hline Tea, iced tea, or coffee & One mug or medium coffee \\
\hline Slurpees, slushies, or snow cones & One small slurpee \\
\hline Shakes & One small milkshake \\
\hline Water & One cup or small bottle of water \\
\hline
\end{tabular}

school, evenings, and spare time, for example: if you did 45 minutes of hard physical activity on Monday, you need to fill in the 0 hour circle and the 45 minutes circle" and "MODERATE physical activities are lower intensity activities such as walking, biking to school, and recreational swimming. Mark how many minutes of moderate physical activity you did on each of the last 7 days. Do not include time spent doing hard physical activities" with a corresponding bubble sheet to fill in hours and minutes spent in activity. ${ }^{30}$ This was re-coded as a binary variable $(0,1)$ where $1=$ those individuals who achieved 90 minutes of moderate or vigorous physical activity for each of the 7 days of the previous week, and $0=$ those who achieved less than this criteria, in accordance with recommendations from Canada's Physical Activity Guidelines at the time of the survey.

\section{Data Analysis}

Respondents for whom either age or sex was missing were excluded from the analysis $(\mathrm{N}=266)$. A further 901 were excluded because of incomplete beverage consumption reporting. Differences in the sample profile between regions were assessed. Chi-square tests examined differences in sex, BMI, and physical activity level by region, and analysis of variance (ANOVA) models examined differences in age across regions. Bonferroni corrections were applied to post hoc tests of multiple contrasts. Differences between those who provided beverage information and those who did not provide this information and were subsequently excluded were assessed by chi-square and ANOVA tests.

First, bivariate differences in beverage consumption across regions for all beverage categories were examined using chi-square tests. Beverage consumption was measured as a binary variable where $0=$ no servings of the beverage in the past 24 hours, and $1=$ consumption of any servings of the beverage in the past 24 hours.

Second, logistic regression models were conducted to examine correlates of SSB consumption, with consumption of any SSBs as the dependent variable. Models were adjusted for age, sex, BMI, physical activity, and survey region. To test the effect of categorizing beverage consumption as a binary variable, a parallel set of linear regression models were conducted with the same set of covariates, where beverage consumption was analyzed as a continuous variable $(0,1,2,3$, or $4+$ servings $)$. The pattern of significance was the same. In the interests of length, only the results from the logistic regression model are reported in this article. An additional logistic regression model was conducted in which the "dieting" variable was added to the model. This model was conducted only with the PEI sample given that the question was not asked in the other regions.

Finally, Pearson correlations were used to examine the association between milk and SSB consumption, as well as $100 \%$ fruit juice and SSB consumption. A p-value $<.05$ was considered statistically significant. All analyses were conducted using SPSS (version 19, 2010, IBM Corp., Somers, NY).

\section{RESULTS}

\section{Sample Characteristics}

Sample characteristics are shown in Table 2 . Overall, there were significant differences across regions in the age of the sample $(\mathrm{F}=187.1, \mathrm{p}<.001)$. Participants in Thunder Bay were significantly younger than participants in Hamilton $(\mathrm{t}=17.5, \mathrm{p}<.001)$ and PEI $(t=2.6, p=.03)$. Prince Edward Island participants were also significantly younger than in Hamilton $(\mathrm{t}=14.0, \mathrm{p}<.001)$. Across the 3 regions, $30.0 \%$ of youth met physical activity guidelines of 90 minutes per day; however, there were significant differences in physical activity levels $\left(\chi^{2}=14.5\right.$, $\mathrm{p}=.001)$. Youth in PEI were significantly less likely to meet physical activity guidelines than youth in Thunder Bay $\left(\chi^{2}=8.3, p=.012\right)$ and Hamilton $\left(\chi^{2}=13.7, p<.001\right)$. Across the 3 regions, $22.9 \%$ of youth were either at risk for overweight or overweight; however, rates of at risk of overweight or overweight significantly differed between regions $\left(\chi^{2}=20.2\right.$, $\mathrm{p}<.001)$. Youth in Hamilton were significantly less likely to be at risk for overweight or overweight than youth in Thunder Bay $\left(\chi^{2}=6.9, \mathrm{p}=.024\right)$ and PEI $\left(\chi^{2}=19.2, p<.001\right)$.

Analyses were conducted to examine differences between the current sample and those who did not supply beverage information and were excluded. Excluded participants were more likely to be boys $\left(54.7 \%\right.$ boys vs. $49.4 \%$ girls, $\left.\chi^{2}=35.1, p<.001\right)$ 
Table 2. Sample Characteristics $(\mathrm{N}=10,188)$

\begin{tabular}{lccc}
\hline & $\begin{array}{c}\text { Thunder Bay } \\
(\mathbf{N}=\mathbf{2 8 1 7})\end{array}$ & $\begin{array}{c}\text { Hamilton } \\
\mathbf{( N = 4 8 3 3 )}\end{array}$ & $\begin{array}{c}\text { PEI } \\
\mathbf{( N = 2 5 3 8 )}\end{array}$ \\
\hline Age & & & \\
13 & $1.3 \%(37)$ & $0.4 \%(18)$ & $17.9 \%(455)$ \\
14 & $32.6 \%(918)$ & $22.9 \%(1105)$ & $18.8 \%(476)$ \\
15 & $32.4 \%(912)$ & $24.6 \%(1189)$ & $19.6 \%(498)$ \\
16 & $24.2 \%(681)$ & $24.8 \%(1200)$ & $19.3 \%(491)$ \\
17 & $7.1 \%(201)$ & $20.0 \%(967)$ & $18.4 \%(466)$ \\
18 & $2.4 \%(68)$ & $7.3 \%(354)$ & $6.0 \%(152)$ \\
Mean age in years (SD) & $15.1(1.1)$ & $15.6(1.2)$ & $15.2(1.5)$ \\
Sex & & & \\
Girls & $50.2 \%(1414)$ & $49.9 \%(2412)$ & $52.3 \%(1328)$ \\
Boys & $49.8 \%(1403)$ & $50.1 \%(2421)$ & $47.7 \%(1210)$ \\
BM|* & & & \\
Underweight & $2.2 \%(61)$ & $3.1 \%(152)$ & $2.6 \%(67)$ \\
Healthy weight & $55.0 \%(1548)$ & $57.7 \%(2788)$ & $57.7 \%(1465)$ \\
At risk for overweight & $10.2 \%(288)$ & $8.6 \%(414)$ & $11.8 \%(299)$ \\
Overweight & $7.6 \%(213)$ & $7.4 \%(357)$ & $9.2 \%(234)$ \\
Missing & $25.1 \%(707)$ & $23.2 \%(1122)$ & $18.6 \%(473)$ \\
Physical Activity ${ }^{\dagger}$ & & & \\
Meets guidelines & $28.9 \%(814)$ & $29.9 \%(1445)$ & $25.3 \%(643)$ \\
Does not meet & $65.4 \%(1842)$ & $65.8 \%(3182)$ & $68.6 \%(1742)$ \\
$\quad$ guidelines & & & \\
Missing & $5.7 \%(161)$ & $4.3 \%(206)$ & $6.0 \%(153)$ \\
Currently eating less to & & & \\
$\quad$ lose weight? & & & \\
Yes & Not asked & Not asked & $18.2 \%(461)$ \\
No & & & $79.0 \%(2005)$ \\
Missing & & & $2.8 \%(72)$ \\
\hline
\end{tabular}

*BMI Categories: Underweight $=$ Below 5 th percentile for age, Healthy weight $=5$ to $85 \%$ for age, At risk for overweight $=85$ to $95 \%$ for age, and Overweight $=>95 \%$ for age.

${ }^{\dagger}$ Physical activity categories: Meets guidelines=Participates in 90 minutes of moderate to vigorous physical activity per day for 7 days in the previous week, Does not meet guidelines = Does not participate in at least 90 minutes of moderate to vigorous physical activity per day for 7 days in the previous week, in accordance with previous recommendations from Canada's Physical Activity Guidelines.

and were significantly more likely to be excluded if they were from Thunder Bay $(30.2 \%$ vs. $27.7 \%$ in final sample, $\left.\chi^{2}=6.5, p=0.01\right)$ and PEI $(27.7 \%$ vs. $24.9 \%$ in final sample, $\left.\chi^{2}=21.5, \mathrm{p}<.001\right)$ compared to Hamilton.

\section{Beverage Consumption}

Table 3 shows consumption of beverage servings over the past 24 hours. Figure 1 depicts the proportion of the total population consuming at least 1 serving of each of the beverage categories, as well as the summary variable. Across all 3 regions, participants were most likely to report consuming at least 1 serving of water $(93.4 \%)$, followed by milk, chocolate milk, or soy products $(83.7 \%)$. The most commonly consumed SSBs were fruit-flavored drinks $(51.6 \%)$ and regular, nondiet pop (44.4\%). Overall, $80.3 \%$ of youth reported consuming at least 1 SSB in the last 24 hours: $36.2 \%$ reported consuming 1 to 2 drinks and $44.1 \%$ reported consuming 3 or more SSBs.

Youth in PEI were significantly less likely to consume a SSB compared to youth in Thunder
Bay $\left(\chi^{2}=64.1, p<.001\right)$ and Hamilton $\left(\chi^{2}=16.5\right.$, $\mathrm{p}<.001)$. Significantly fewer youth in Hamilton consumed SSBs compared to youth in Thunder Bay $\left(\chi^{2}=25.6, \mathrm{p}<.001\right)$.

\section{Correlates of Beverage Consumption}

Logistic regression models were conducted to examine factors associated with SSB consumption $(0=$ no SSBs in the previous day, $1=$ consumption of any SSBs in the previous day), using 5 covariates: age, sex, BMI, physical activity level, and survey region. Boys were more likely to consume SSBs in the previous day than girls $(\mathrm{OR}=2.2,95 \% \mathrm{CI}=2.0$ $2.5)$. Older youth, $(\mathrm{OR}=0.89,95 \% \mathrm{CI}=0.85-0.93)$ and those who met the required daily physical activity guidelines of 90 minutes per day $(\mathrm{OR}=0.70$, 95\% CI $=0.61-0.80)$ consumed fewer SSBs. Youth in Thunder Bay consumed significantly more SSBs than both Hamilton $(\mathrm{OR}=0.75,95 \% \mathrm{CI}=0.64-0.87)$ and PEI $(\mathrm{OR}=0.58,95 \% \mathrm{CI}=0.49-0.69)$, and youth in Hamilton consumed more SSBs than youth in PEI $(\mathrm{OR}=0.78,95 \% \mathrm{CI}=0.68-0.89)$.

\section{Dieting Behavior}

When the above model was run including the response to the question: "Are you currently eating less to lose weight," using only responses from the PEI survey, youth who reported dieting were less likely to consume SSBs $(\mathrm{OR}=0.66,95 \% \mathrm{CI}=0.50-0.88)$.

\section{Beverage Displacement}

Milk consumption had a very modest but statistically significant positive association with SSB consumption $(\mathrm{r}=.06, \mathrm{p}<.001)$. Consumption of $100 \%$ fruit juice had a similar positive correlation with SSB consumption $(\mathrm{r}=0.10, \mathrm{p}<.001)$.

\section{DISCUSSION}

This study suggests that more than $80 \%$ of youth in 3 geographically distinct regions of Canada consumed SSBs daily. The current finding is similar to the proportion of youth who consume SSBs in the United States, where daily SSB consumption rates have recently been estimated at $84 \%{ }^{9}$

No significant association was found between BMI and SSB consumption in this study. This is consistent with most cross-sectional studies; ${ }^{21,25}$ however, 1 cross-sectional study among Canadian children is an exception and has detected significant associations between BMI and SSB consumption. ${ }^{27}$ This study used a 24-hour recall with the assistance of a dietitian, as well as direct measures of BMI, which may account for the differing results.

Lack of an observed association between BMI and SSB consumption in this study may be a product 


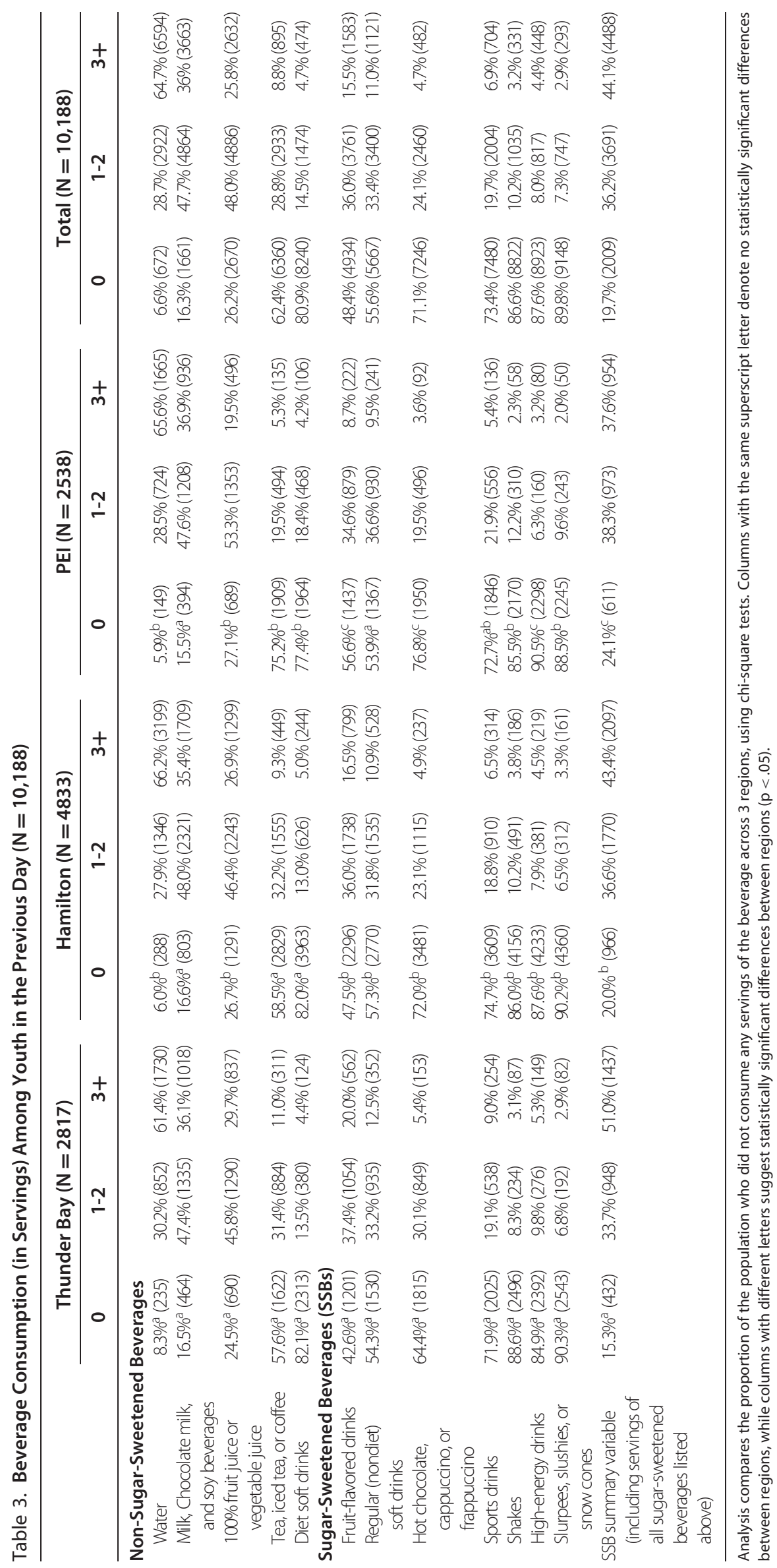




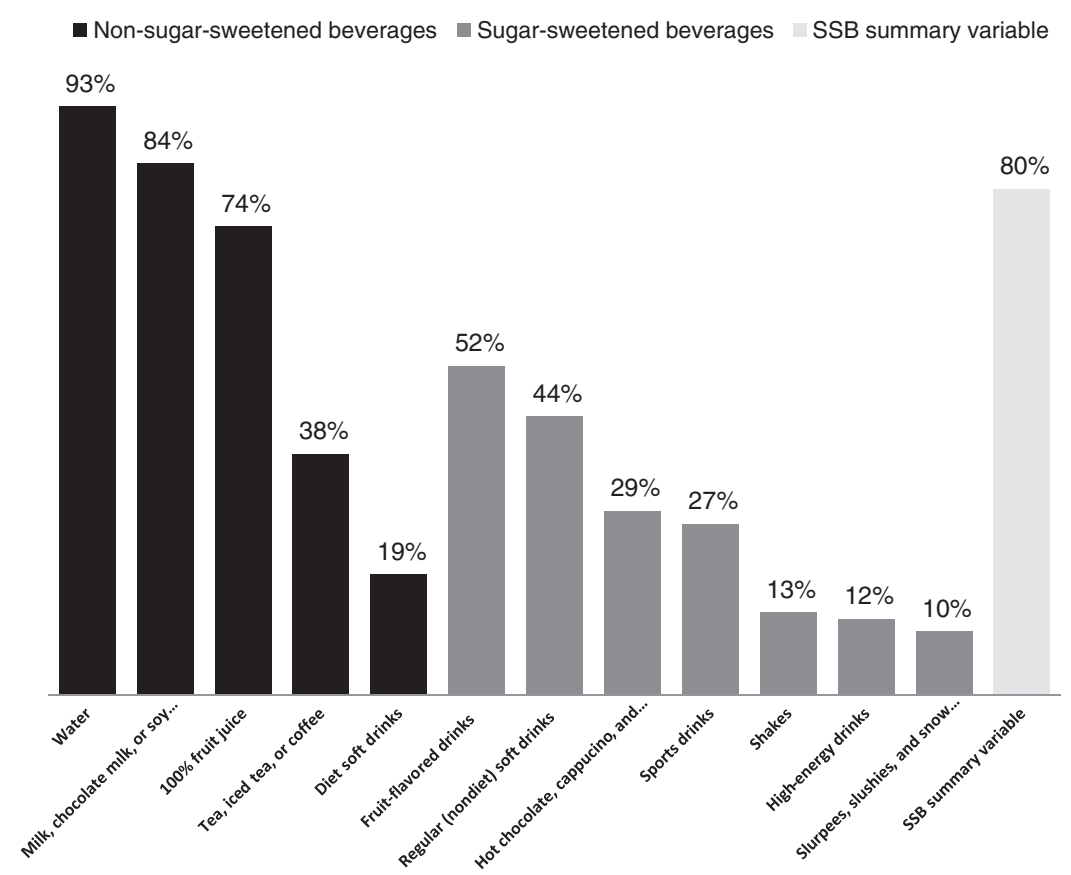

of systematic underreporting in both weight and beverage consumption. Youth tend to underestimate their weight in self-report measures, especially girls and overweight adolescents. ${ }^{33}$ However, the selfreported height and weight questions used in the SHAPES survey have been validated for this population, and show adequate reliability. ${ }^{30}$ Similarly, a study conducted with Canadian adolescents found evidence of underreporting energy intake, with girls underreporting more than boys, and increasing levels of underreporting with increasing BMI status in both boys and girls. ${ }^{34}$ These findings suggest that the association between BMI and SSB consumption in this study may present as lower than the true value of the association.

Previous literature from nationally representative Canadian surveys suggests that as youth get older, they consume increasing amounts of SSBs. ${ }^{12,35}$ In contrast, this study showed a slight decrease in beverage consumption with increased age among youth. This study also suggested that boys consumed more SSBs than girls, which has been shown in previous cross-sectional nationally representative Canadian studies. ${ }^{12,35,36}$ The findings also indicate that youth who were dieting were less likely to consume SSBs. This finding is not surprising, as those who are looking to lose weight may be conscientiously consuming fewer SSBs to decrease caloric intake.

This study did not find that high SSB consumption was related to drinking less milk or $100 \%$ fruit juice. In fact, there were modest positive correlations, showing that individuals who drank slightly more servings of SSBs consumed slightly higher amounts of milk and $100 \%$ fruit juice. This small positive association has been found in a previous Canadian study, but this result is not consistent with the majority of previous cross-sectional research examining this relationship in milk, which has found that milk consumption is often significantly lower when youth consume more sweetened beverages. ${ }^{11,21,36}$ A longitudinal study of Canadian children from 1991 to 2004 found a significant negative association between milk consumption and consumption of noncarbonated soft drinks, but no significant association between milk intake and carbonated soft drinks or total soft drinks ${ }^{37}$ A longitudinal study in the United States showed that milk consumption and fruit juice consumption were inversely related to SSB consumption in some children. ${ }^{38}$ The nature of these differences is unclear, although it may be a result of differing definitions of SSB categories within the literature.

\section{Strengths and Limitations}

This study has several limitations common to selfreport surveys conducted with youth. As mentioned previously, the use of self-report measures may bias the association of BMI and SSB consumption toward the null, and provide a conservative estimate of the association. The use of a single 24-hour food-frequency questionnaire only includes beverage consumption on the previous day, which may not be representative of typical consumptive behavior, and may be 
better examined through the use of multiple-day questionnaires. There is an inherent limitation with the use of food-frequency questionnaires among youth, although the SHAPES beverage consumption module demonstrated adequate validity when compared to a Web-based 24-hour dietary recall.

The measures used to assess SSB could also benefit from additional specificity. For example, the "tea, coffee, and iced tea" category may be better described by removing iced tea, as many iced tea products contain an amount of calories equivalent to regular soda or fruit-flavored beverages. Also, different categories for the number of servings were used across survey sites $(0,1,2,3,4-5$, and $6+$ compared to 0,1 , $2,3,4,5$, and $6+$ ), and did not permit the calculation of a total number of beverages consumed.

The reason for different patterns of beverage consumption between regions is not clear. Variables examining policy around obesity, including healthy eating and physical activity programs, were not included in the analysis. Including environmental or ecological measures of the school environment and relevant policies would provide important context for the individual-level surveys and would complement the self-report surveys.

There are inherent limitations with the use of a cross-sectional study, as this study design does not allow establishment of causality. Finally, this sample was not randomly selected and used a convenience sample in Hamilton and Thunder Bay, and thus is not representative of Ontario or on a national scale. In addition, the sample from PEI included 2 extra grades; however, it appears that this did not necessarily skew the average age profile in this group. Given the large number of participants, and the use of several schools within several distinct regions, it is likely that the results have some generalizability to the population at large. Strengths of this study include a broad definition of SSBs, comparisons across regions, and the large sample size within regions.

\section{Conclusion}

This study indicates that the vast majority of Canadian youth are consuming SSBs on a daily basis, many in high volumes. The findings also suggest that youth in certain demographic groups such as boys and younger age categories consume greater quantities of SSBs. There is a need for longitudinal research in Canada to monitor SSB consumption and to further examine its role in the development of overweight and obesity among Canadian youth, as well as interventions that may lower consumption rates.

\section{IMPLICATIONS FOR SCHOOL HEALTH}

Given the high calories and low nutritional content of most SSBs, the high rate of daily consumption of SSBs among Canadian school-aged children is of concern. There may be program and policy efforts that could play a role in decreasing the high numbers of youth consuming SSBs daily. ${ }^{39}$ Several policy measures have already been implemented to lower SSB consumption among youth in Canada. For example, mandatory nutrition standards for beverages sold in schools are in place in several provinces across Canada, including recent introduction of Policy/Program Memorandum 150, a comprehensive school food and beverage policy in Ontario. ${ }^{40}$ Bans on vending machines that sell sugar-sweetened drinks have also been implemented in a number of school districts, including in elementary schools in PEI. These policies may modify SSB consumption, and further research into how these policy changes affect consumption should be considered a priority.

\section{Human Subjects Approval Statement}

Approval for the questionnaires was obtained from each participating school board, and from the province. Each study has received clearance from the University of Waterloo Office of Research Ethics, as well as respective ethics boards, and the Provincial Ethics Board for PEI.

\section{REFERENCES}

1. World Health Organization. Obesity and Overweight Fact Sheet No. 311. Available at: http://www.who.int/mediacentre/ factsheets/fs311/en/index.html. Accessed September 28, 2012.

2. Public Health Agency of Canada. Obesity in Canada: a joint report from the Public Health Agency of Canada and the Canadian Institute for Health Information. Available at: http://www. phac-aspc.gc.ca/hp-ps/hl-mvs/oic-oac/assets/pdf/oic-oaceng.pdf. Accessed September 28, 2012.

3. Statistics Canada. Canadian Health Measures Survey: body composition and fitness. Available at: http://www.statcan. gc.ca/daily-quotidien/100113/dq100113a-eng.htm. Accessed September 28, 2012.

4. Lobstein T, Baur L, Uauy R. Obesity in children and young people: a crisis in public health. Obes Rev. 2004;5(suppl 1): 4-85.

5. Singh AS, Mulder C, Twisk JWR, van Mechelen W, Chinapaw MJM. Tracking of childhood overweight into adulthood: a systematic review of the literature. Obes Rev. 2008;9(5):474-488.

6. Raine KD. Overweight and Obesity in Canada: A Population Health Perspective. Ottawa, Canada: Canadian Institute for Health Information; 2004.

7. Public Health Agency of Canada. Curbing childhood obesity: a federal, provincial and territorial framework for action to promote health weights. Available at: http://www.phacaspc.gc.ca/hp-ps/hl-mvs/framework-cadre/index-eng.php. Accessed September 28, 2012.

8. Brownell KD, Frieden TR. Ounces of prevention - the public policy case for taxes on sugared beverages. $N$ Engl $J$ Med. 2009;360(18):1805-1808.

9. Wang YC, Bleich SN, Gortmaker SL. Increasing caloric contribution from sugar-sweetened beverages and 100\% fruit juices among US children and adolescents, 1988-2004. Pediatrics. 2008;121(6):el604-e1614.

10. Guthrie JF, Morton JF. Food sources of added sweeteners in the diets of Americans. J Am Diet Assoc. 2000;100(1):43-51. 
11. Danyliw AD, Vatanparast H, Nikpartow N, Whiting SJ. Beverage intake patterns of Canadian children and adolescents. Public Health Nutr. 201 1;14(11):1961-1969.

12. Garriguet D. Beverage consumption of children and teens. Health Rep. 2008;19(4):17-22.

13. Merchant AT, Tripathi A, Pervaiz F. Available energy from soft drinks: more than the sum of its parts. Public Health Nutr. 2010;13(12):1997-1999.

14. Malik VS, Popkin BM, Bray GA, Despres JP, Willet WC, $\mathrm{Hu}$ FB. Sugar-sweetened beverages and risk of metabolic syndrome and type 2 diabetes: a meta-analysis. Diabetes Care. 2010;33(11):2477-2483.

15. Malik VS, Popkin BM, Bray GA, Despres J-P, Willet WD, Hu FB. Sugar-sweetened beverages, obesity, type 2 diabetes mellitus, and cardiovascular disease risk. Circulation. 2010;121(11):13561364.

16. Brown IJ, Stamler J, Van Horn L, et al. Sugar-sweetened beverage, sugar intake of individuals, and their blood pressure: international study of macro/micronutrients and blood pressure. Hypertension. 201 1;57(4):695-701.

17. Bachman CM, Baranowski T, Nicklas TA. Is there an association between sweetened beverages and adiposity? Nutr Rev. 2006;64(4):153-174.

18. Wolff E, Dansinger ML. Soft drinks and weight gain: how strong is the link? Medscape J Med. 2008;10(8):189.

19. Mattes RD, Shikany JM, Kaiser KA, Allison DB. Nutritively sweetened beverage consumption and body weight: a systematic review and meta-analysis of randomized experiments. Obes Rev. 2011;12(5):346-365.

20. Malik VS, Schulze MB, Hu FB. Intake of sugar-sweetened beverages and weight gain: a systematic review. Am J Clin Nutr. 2006;84(2):274-288.

21. Vartanian LR, Schwartz MB, Brownell KD. Effects of soft drink consumption on nutrition and health: a systematic review and meta-analysis. Am J Public Health. 2007;97(4): 667-675.

22. Forshee RA, Anderson PA, Storey ML. Sugar-sweetened beverages and body mass index in children and adolescents: a meta-analysis. Am J Clin Nutr. 2008;87(6):1662-1671.

23. Malik VS, Willett WC, Hu FB. Sugar-sweetened beverages and BMI in children and adolescents: reanalyses of a metaanalysis. Am J Clin Nutr. 2009;89(1):438-439 author reply 439-440.

24. Mundt CA, Baxter-Jones ADG, Whiting SJ, Bailey DA, Faulkner RA, Mirwald RL. Relationships of activity and sugar drink intake on fat mass development in youths. Med Sci Sports Exerc. 2006;38(7):1245-1254.

25. Janssen I, Katzmarzyk PT, Boyce WF, et al. Comparison of overweight and obesity prevalence in school-aged youth from 34 countries and their relationships with physical activity and dietary patterns. Obes Rev. 2005;6(2):123-132.

26. Dubois L, Farmer A, Girard M, Peterson K. Regular sugarsweetened beverage consumption between meals increases risk of overweight among preschool-aged children. J Am Diet Assoc. 2007; 107(6):924-934.

27. Gillis LJ, Bar-Or O. Food away from home, sugar-sweetened drink consumption and juvenile obesity. J Am Coll Nutr. 2003;22(6):539-545.

28. Nielsen SJ, Popkin BM. Changes in beverage intake between 1977 and 2001. Am J Prev Med. 2004;27(3):205-210.

29. Statistics Canada. 2001 Community Profiles. Available at: http:// wwwl2.statcan.ca/english/Profil01/CP01/Index.cfm?Lang=E. Accessed September 28, 2012.

30. Wong SL, Leatherdale ST, Manske SR. Reliability and validity of a school-based physical activity questionnaire. Med Sci Sports Exerc. 2006;38(9):1593-1600.

31. Kuczmarski RJ, Ogden CL, Grummer-Strawn LM, et al. CDC growth charts: United States. Adv Data. 2000;314:1-27.

32. Clemente MD, Manske S, Naylor P-J, Hanning RM. Technical report: relative validity of the School Health Action, Planning and Evaluation System (SHAPES) Questionnaire and Waterloo Eating Behaviour 24 Hour Recall Questionnaire (WEB-Q) for assessing adolescent beverage consumption. 2011. Available at: http://www.davidhammond.ca/downloads/Papers/2012\%20 Clement\%20et\%20al.pdf. Accessed November 23, 2012.

33. Sherry B, Jefferds ME, Grummer-Strawn LM. Accuracy of adolescent self-report of height and weight in assessing overweight status: a literature review. Arch Pediatr Adolesc Med. 2007;161(12):1154-1161.

34. Vance VA, Woodruff SJ, McCargar LJ, Husted J, Hanning RM. Self-reported dietary energy intake of normal weight, overweight and obese adolescents. Public Health Nutr. 2009;12(2):222-227.

35. Boyce W. Young People in Canada: Their Health and WellBeing. Ottawa, Canada: Public Health Agency of Canada; 2004 Available at: http://www.phac-aspc.gc.ca/hp-ps/dca-dea/ publications/hbsc-2004/chapter_7-eng.php. Accessed September 28, 2012.

36. Barr SI. Associations of social and demographic variables with calcium intakes of high school students. J Am Diet Assoc. 1994;94(3):260-269.

37. Vatanparast H, Lo E, Henry CJ, Whiting SJ. A negative trend in calcium intake was accompanied by a substitution of milk by noncarbonated soft drinks in Canadian female students. Nutr Res. 2006;26(7):325-329.

38. Blum JW, Jacobsen DJ, Donnelly JE. Beverage consumption patterns in elementary school aged children across a two-year period. J Am Coll Nutr. 2005;24(2):93-98.

39. Woodruff SJ, Hanning RM, McGoldrick K. The influence of physical and social contexts of eating on lunch-time food intake among southern Ontario, Canada, middle school students. J Sch Health. 2010;80(9):421-428.

40. Ontario Ministry of Education. Policy/Program Memorandum No. 150. School Food and Beverage Policy. Available at: http://www.edu.gov.on.ca/extra/eng/ppm/ppm150.pdf. Accessed September 28, 2012. 